\title{
AVALIAÇÃO DA IMPLANTAÇÃO DE UM SISTEMA FOTOVOLTAICO NO SETOR DE PANIFICAÇÃO
}

DOI: 10.37702/2175-957X.COBENGE.2021.3417

Bruno Xavier Barros - brunoxb2009@gmail.com

Universidade Federal de Pernambuco

Rua Dr. Alexandrino Cabral 188

55665-000 - Camocim de São Félix - PE

Davi Leão de Sabóia - davileao2@gmail.com

Universidade Federal de Pernambuco

Rua João Cardoso Aires 327

51130-300 - Recife - PE

Resumo: $O$ presente trabalho avalia a implementação de um sistema de geração fotovoltaico para suprir todo o consumo de energia elétrica de um empreendimento comercial no setor de panificação. O sistema em questão foi desenvolvido com a perspectiva de se apresentar como uma solução viável para os altos custos de energia elétrica que o empreendimento tem tido nos últimos anos, e se possível, deste modo, tornar-se autossuficiente na produção de energia. Assim, através de uma pesquisa do tipo estudo de caso, foi realizada a coleta dos seguintes dados: tarifa, custo e consumo energético da padaria. Para a análise de viabilidade econômica foram utilizados os métodos de análise de investimento: valor presente líquido, taxa interna de retorno e payback. Foi possível verificar que de fato há viabilidade na implementação do sistema de geração fotovoltaico no empreendimento.

Palavras-chave: Sistema fotovoltaico, geração distribuída, setor de panificação. 


\section{INTRODUÇÃO}

O Brasil possui um dos melhores recursos solares do planeta (PEREIRA et al, 2017). Em 2019, assumiu a 16 ${ }^{\text {a }}$ posição no ranking mundial da fonte solar fotovoltaica, segundo a Associação Brasileira de Energia Solar Fotovoltaica (ABSOLAR), com base em dados da Agência Internacional de Energias Renováveis (IRENA). O ranking é liderado pela China, seguida dos Estados Unidos e Japão (ABSOLAR, 2020b online).

Contudo, apesar da posição ocupada no ranking, o desempenho do Brasil está aquém de seu potencial solar, demonstrando que ainda há bastante espaço para a ampliação da participação da geração fotovoltaica na matriz energética. Pode-se dizer que "o investimento inicial para a implantação desses sistemas ainda é alto, e grande parte da população não tem acesso a linhas de financiamento adequadas para obtê-los" (DANTAS, 2020, p. 48).

Dado o interesse de consumidores em geral pela energia solar fotovoltaica, que "é a fonte de energia que mais cresce no mundo" (ABSOLAR, 2020b online), este trabalho avalia a implementação de um sistema de geração fotovoltaico para suprir todo o consumo de energia elétrica de um empreendimento comercial no setor de panificação.

Este texto foi dividido em três partes, na primeira são contextualizados os conceitos e ideias que envolvem o projeto da implantação das placas fotovoltaicas, bem como são trazidos os principais acontecimentos que contribuíram para o aumento das instalações de sistemas de energia fotovoltaicos no Brasil; na segunda, é apresentado o estudo de caso; e, na terceira parte, são expostas as análises e interpretações dos dados coletados.

\section{A GERAÇÃO FOTOVOLTAICA DE ENERGIA NO BRASIL}

Pereira et al (2017) afirmam que o sistema elétrico brasileiro é essencialmente hidrotérmico, de grande porte e com predominância de usinas hidroelétricas, conforme apresentado na figura 1, as quais são controladas por múltiplos proprietários: empresas das regiões Sul, Sudeste, Centro-Oeste, Nordeste e parte da região Norte.

Figura 1 - Matriz Elétrica Brasileira 2019

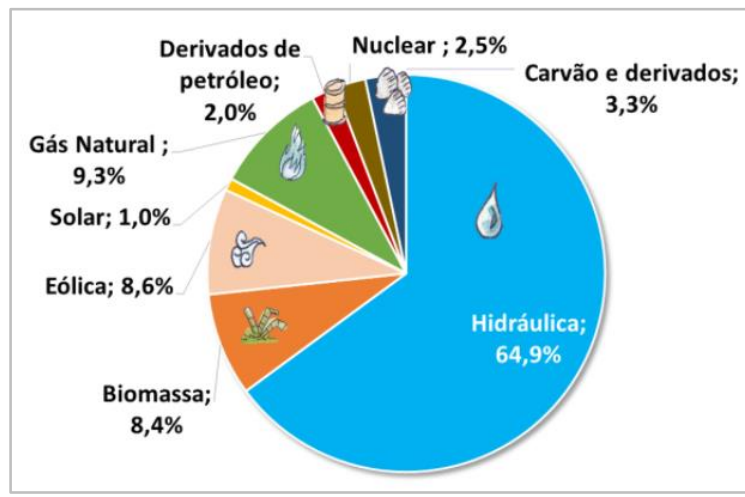

Fonte: Balanço Energético Nacional Interativo (BEN Interativo) (EPE, 2020). 
Ainda segundo Pereira et al (2017), as termoelétricas e as hidroelétricas são consideradas "fontes firmes", pois são capazes de garantir o atendimento da demanda de carga típica do sistema, enquanto as fontes renováveis como, por exemplo, a eólica e a solar fotovoltaica são consideradas "fontes intermitentes" de energia, devido à grande variabilidade temporal e espacial.

O Brasil tem grande potencial natural ${ }^{1}$ para desenvolver e usufruir desses recursos, principalmente no semiárido ${ }^{2}$ brasileiro, uma vez que esta região "se localiza em latitudes próximas ao Equador, região geográfica da Terra que recebe maiores quantidades de radiação solar" (DANTAS, 2020, p.12), como pode ser observado na figura 2.

Figura 2 - Incidência solar média diária no Brasil

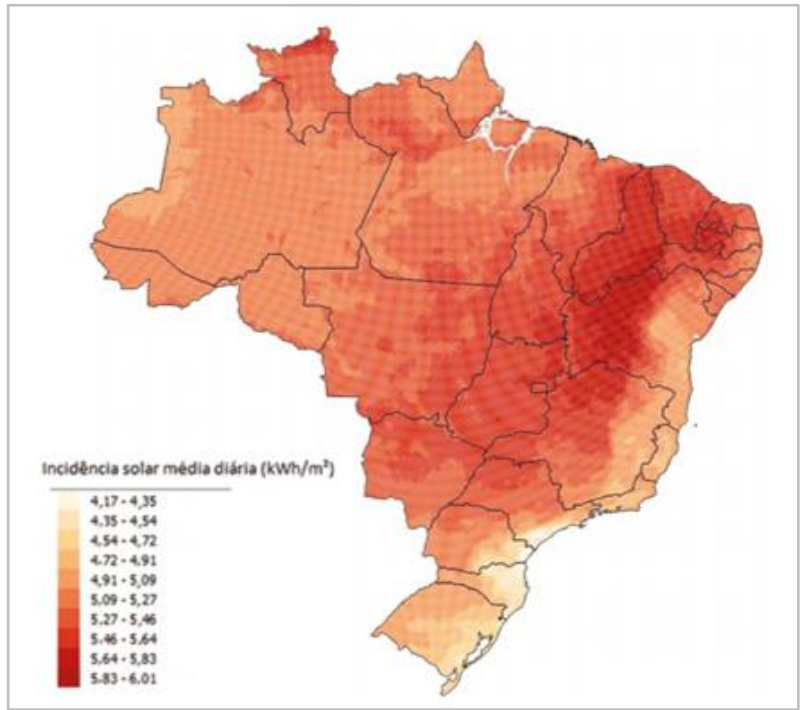

Fonte: CPTEC e INPE (2016) apud Dantas

(2020, p. 11).

\subsection{A radiação solar}

A energia solar é o recurso mais abundante em nosso planeta e seu uso é uma das alternativas energéticas mais promissoras na atualidade (ABSOLAR, 2020b online).

A rigor, a energia proveniente do Sol não é renovável, mas uma fonte inesgotável levando em consideração a escala de tempo da vida no planeta Terra. O Sol é uma estrela de tamanho médio e a energia irradiada por ele é consequência das reações de fusão nuclear dos átomos de Hidrogênio (representam cerca de $75 \%$ da composição do Sol) para formar Hélio (cerca de $25 \%$ da composição do Sol). A taxa de energia emitida pelo Sol é aproximadamente constante há bilhões de anos com uma potência atual da ordem de 3,86. $1026 \mathrm{~W}$. A temperatura efetiva na superfície do Sol é da ordem de $5778 \mathrm{~K}\left(5505^{\circ} \mathrm{C}\right)$ (PEREIRA et al, 2017, p. 15).

Segundo os autores, a disponibilidade do recurso energético solar e sua variabilidade espacial e temporal depende da latitude local e da posição no tempo (hora do

\footnotetext{
1 "No local menos ensolarado do Brasil, é possível gerar mais eletricidade solar do que no local mais ensolarado da Alemanha, por exemplo" (PEREIRA et al, 2017, p. 57).

2 "O semiárido abrange 1.262 municípios com uma área de $969.589,4 \mathrm{~km}^{2}$, correspondente a quase $90 \%$ da região Nordeste (nos estados do Piauí, Ceará, Rio Grande do Norte, Paraíba, Pernambuco, Alagoas, Sergipe e Bahia), além da região setentrional de Minas Gerais" (DANTAS, 2020, p. 8).
} 
dia e dia do ano) e dos processos de interação da radiação solar com os principais constituintes atmosféricos. De toda a radiação solar que chega às camadas atmosféricas superiores, apenas uma fração atinge a superfície do nosso planeta. Essa fração é constituída por uma componente direta e por uma componente difusa (PEREIRA et al, 2017).

A irradiância solar direta apresenta direção de incidência na linha imaginária entre a superfície e o Sol e representa a parcela que não sofreu os processos radiativos de absorção e espalhamento que ocorrem na atmosfera. A componente difusa engloba a radiação proveniente de todas as demais direções que são decorrentes dos processos de espalhamento pelos gases e particulados presentes na atmosfera (PEREIRA et al, 2017, p.19).

A figura 3 ilustra a irradiância $(\mathrm{W} / \mathrm{m} 2)$ assim que ela atinge a atmosfera, bem como seu espalhamento.

Figura 3 - Componentes da irradiância solar

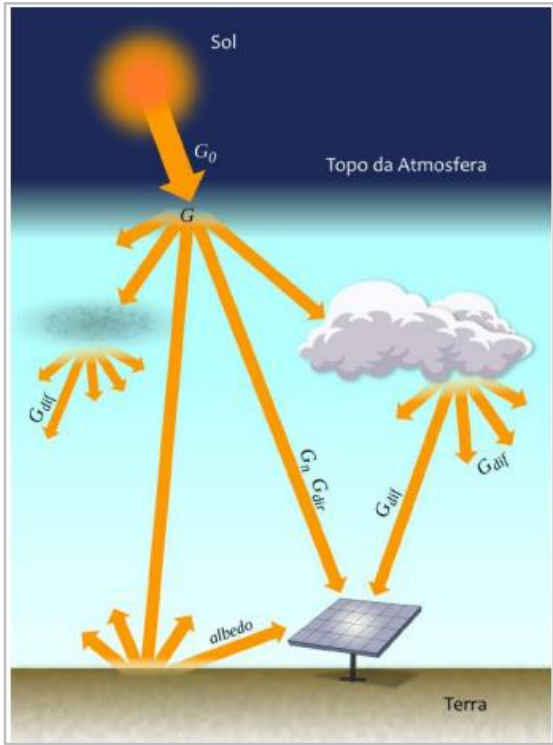

Fonte: Pereira et al (2017, p. 19).

A terminologia adotada pelos autores para explicar a irradiância é a seguinte:

Irradiância extraterrestre $\left(\mathrm{G}_{0}\right)$ : é a taxa de energia incidente por unidade de área em um plano horizontal imaginário situado no topo da atmosfera. É também conhecido como irradiância no topo da atmosfera ou G Irradiância direta normal $\left(\mathrm{G}_{n}\right)$ : também conhecida como $\mathrm{DNI}$, é a taxa de energia por unidade de área proveniente diretamente do Sol que incide perpendicularmente à superfície.

Irradiância difusa horizontal $\left(\mathrm{G}_{\mathrm{dif}}\right)$ : é a taxa de energia incidente sobre uma superfície horizontal por unidade de área, decorrente do espalhamento do feixe solar direto pelos constituintes atmosféricos (moléculas, material particulado, nuvens, etc.).

Irradiância direta horizontal $\left(\mathrm{G}_{\mathrm{dir}}\right)$ : é a taxa de energia por unidade de área do feixe solar direto numa superfície horizontal. Pode ser determinada como 
o produto entre a irradiância direta normal (DNI) e o cosseno do ângulo zenital solar.

Irradiância global horizontal $(G)$ : é a taxa de energia total por unidade de área incidente numa superfície horizontal. A irradiância global é dada pela soma $G=G_{\text {dif }}+G_{\text {dir }}$ ou $G=G_{\text {dif }}+G n \cdot \cos (\theta z)$ onde $\theta z$ é o ângulo zenital. Irradiância no plano inclinado (Gi ): é a taxa de energia total por unidade de área incidente sobre um plano inclinado na latitude do local em relação à superfície da Terra (PEREIRA et al, 2017, p. 19).

Portanto, considerando que "a duração do dia e a quantidade de energia solar incidente em um ponto qualquer da superfície terrestre apresenta variabilidade temporal característica de dois ciclos: o ciclo anual e o ciclo diário" (PEREIRA et al, 2017, p. 15-16), antes de ser instalado qualquer sistema fotovoltaico faz-se necessário um estudo prévio no empreendimento, com vistas a conhecer a posição solar e, desse modo, definir adequadamente a angulação dos painéis solares, evitando, assim, pontos de sombreamento e garantindo o melhor aproveitamento da irradiação.

\subsection{A regulamentação e o crescimento da geração de energia fotovoltaica no Brasil}

Desde 2012 houve um grande crescimento da área de geração de energia solar fotovoltaica ${ }^{3}$, especialmente no tocante a empreendimentos de pequeno porte que geram energia elétrica em unidades consumidoras (UCs) conectadas à rede de distribuição. Com a Resolução Normativa - REN no 482/2012, alterada pela REN ANEEL no 687/2015, foram estabelecidas as condições gerais para o acesso à microgeração distribuída (centrais geradoras de energia elétrica com potência instalada até $75 \mathrm{~kW}$ ) e minigeração distribuída (centrais geradoras com potência instalada superior a $75 \mathrm{~kW}$ e menor ou igual a $5 \mathrm{MW}$ ), e criou o Sistema de Compensação de Energia Elétrica (Net metering).

A geração distribuída (GD) "é caracterizada pela instalação de geradores de pequeno porte, normalmente a partir de fontes renováveis ou mesmo utilizando combustíveis fósseis, localizados próximos aos centros de consumo de energia elétrica" (ANEEL, 2016, p. 7). O Sistema Net metering "permite que a energia excedente gerada pela unidade consumidora com micro ou minigeração seja injetada na rede da distribuidora, a qual funcionará como uma bateria, armazenando esse excedente" (ANEEL, 2016, p. 15),

Caso a energia injetada na rede seja maior que a consumida, o responsável pela UC deve pagar apenas a taxa mínima ${ }^{4}$, ficando com um crédito de energia ( $\mathrm{kWh}$ ), cuja validade é de 60 meses e pode ser utilizado para abater o consumo na fatura dos meses subsequentes na própria UC ou para compensar o consumo de outras unidades consumidoras, observando o enquadramento apresentado no quadro 1:

\footnotetext{
${ }^{3}$ O sistema fotovoltaico segue dois modelos de geração e consumo de energia, sendo eles: o sistema conectado à rede (on-grid) e o não conectado à rede ou sistema isolado (off-grid), que opera com o suporte de baterias ou outros sistemas para armazenar a energia excedente produzida e, assim, garantir o uso em períodos com pouca irradiação solar ou no período noturno (ABSOLAR, 2017 online). O sistema off-grid de pequeno porte (solar + armazenamento) ou híbrido, voltado para produtores independentes (fonte renovável + armazenamento), apresentam um custo inicial maior, mas são uma alternativa viável em localidades remotas ou rurais (ABSOLAR, 2020a online).

${ }^{4}$ Para consumidores de baixa tensão (grupo B), a tarifa a ser paga corresponde ao valor em reais de: $30 \mathrm{kWh}$, no caso de ligações monofásicas; $50 \mathrm{kWh}$, no caso de ligações bifásicas; ou $100 \mathrm{kWh}$, no caso de ligações trifásicas. De forma análoga, consumidores conectados em alta tensão (grupo A) devem quitar apenas a parcela da fatura correspondente à demanda contratada (ANEEL, 2016).
} 
Quadro 1: Modalidades da geração distribuída

\begin{tabular}{|c|c|}
\hline Modalidades & Definições \\
\hline $\begin{array}{c}\text { Geração } \\
\text { compartilhada }\end{array}$ & $\begin{array}{l}\text { caracterizada pela reunião de consumidores, dentro da mesma área de } \\
\text { concessão ou permissão, por meio de consórcio ou cooperativa, } \\
\text { composta por pessoa física ou jurídica, que possua UC com } \\
\text { microgeração ou minigeração distribuída em local diferente das } \\
\text { unidades consumidoras nas quais a energia excedente será } \\
\text { compensada. }\end{array}$ \\
\hline $\begin{array}{l}\text { Autoconsumo } \\
\text { remoto }\end{array}$ & $\begin{array}{l}\text { caracterizado por unidades consumidoras de titularidade de uma mesma } \\
\text { Pessoa Jurídica, incluídas matriz e filial, ou Pessoa Física que possua } \\
\text { UC com microgeração ou minigeração distribuída em local diferente das } \\
\text { unidades consumidoras, dentro da mesma área de concessão ou } \\
\text { permissão, nas quais a energia excedente será compensada. }\end{array}$ \\
\hline $\begin{array}{l}\text { Empreendimento } \\
\text { com múltiplas } \\
\text { unidades } \\
\text { consumidoras } \\
\text { (condomínios) }\end{array}$ & $\begin{array}{l}\text { caracterizado pela utilização da energia elétrica de forma independente, } \\
\text { no qual cada fração com uso individualizado constitua uma UC e as } \\
\text { instalações para atendimento das áreas de uso comum constituam uma } \\
\text { UC distinta, de responsabilidade do condomínio, da administração ou do } \\
\text { proprietário do empreendimento, com microgeração ou minigeração } \\
\text { distribuída, e desde que as unidades consumidoras estejam localizadas } \\
\text { em uma mesma propriedade ou em propriedades contíguas, sendo } \\
\text { vedada a utilização de vias públicas, de passagem aérea ou subterrânea } \\
\text { e de propriedades de terceiros não integrantes do empreendimento. }\end{array}$ \\
\hline
\end{tabular}

Fonte: REN ANEEL № 687 (BRASIL, 2015). Elaboração dos autores.

Dantas (2020) avaliou os impactos da difusão desta geração para os diversos agentes envolvidos. Com relação ao consumidor, que atuará como micro e minigerador, o estudioso apresenta os seguintes custos e benefícios (quadro 2):

Quadro 2: Possíveis impactos da instalação de um sistema fotovoltaico para os consumidores

\begin{tabular}{|c|c|c|}
\hline Impacto (custo) & Tipo & Intensidade \\
\hline Perda de liquidez & Econômico & Baixa \\
\hline Aumento da tarifa de energia & Econômico & Baixa/média \\
\hline Impacto (benefício) & Tipo & Intensidade \\
\hline Forma de investimento em longo prazo & Econômico & Baixa \\
\hline Economia na conta de energia & Econômico & Média \\
\hline $\begin{array}{c}\text { Engajamento em questões energéticas e } \\
\text { ambientais }\end{array}$ & Socioambiental & Baixa \\
\hline
\end{tabular}

Fonte: EPE (2014) apud Dantas (2020, p. 29), com adaptações.

A instalação de painéis solares, como demonstrado no quadro 2, "pode ser considerada como uma forma de investimento, visto que, ao longo do tempo, o valor total da energia produzida pelo sistema supera seu custo. Assim, como em algumas formas de investimentos, uma desvantagem é a perda de liquidez" (DANTAS, 2020, p. 29).

Inegavelmente, as normas regulamentadoras e o sistema de compensação de energia possibilitaram mais autonomia ao consumidor na gestão dos seus gastos com energia elétrica, assim como contribuíram para o crescimento da participação da geração fotovoltaica na matriz energética (SILVA, 2019). Contudo, 
em virtude do modelo tarifário em vigor, o valor mínimo pago pelos consumidores atendidos em baixa tensão e que ingressam no Sistema de Compensação não remunera adequadamente o uso da rede de distribuição. A diferença correspondente é suportada pelas empresas de distribuição e, principalmente, pelos demais consumidores de energia elétrica que não aderem ao Sistema de Compensação (SILVA, 2019, p. 6).

Em 2019, a ANEEL abriu a Consulta Pública ํㅜ $025^{5}$ para discutir modificações nas regras vigentes, entre as quais se destaca a questão do faturamento das unidades consumidoras participantes do sistema de compensação de energia elétrica. Em linhas gerais, aqueles que defendem a revisão do atual modelo alegam que ele gera custos tanto para as distribuidoras quanto para outros consumidores que não possuem um sistema distribuído ${ }^{6}$. Por sua vez, as empresas do setor pedem especial atenção e aprimoramento por parte do regulador e reafirmam a importância das atuais regras para consolidação do mercado de GD.

\subsection{0 sistema fotovoltaico on-grid}

De acordo com o site Energês (2020 online), o sistema fotovoltaico on-grid é composto pelos seguintes componentes:

a) Módulos fotovoltaicos: considerados o coração do sistema fotovoltaico on-grid, são os responsáveis pela captação da radiação solar e transformação em energia elétrica. Eles são dimensionados conforme o consumo de energia da unidade. É possível encontrar muitas variações tecnológicas destes equipamentos no mercado, porém o mais utilizado é o de silício cristalino;

b) Estruturas de fixação: são projetadas para suportar e servir de apoio para os módulos fotovoltaicos. Por isso, é importante que elas sejam resistentes à corrosão, variações térmicas, cargas mecânicas e forças climáticas. Existem no mercado diversos modelos de estruturas. Portanto, a escolha ideal "vai depender do tipo de módulo fotovoltaico a ser instalado, do local de instalação (telhado ou solo) e do material do qual é formado este local (tipo de telhado)".

c) Cabeamento: é responsável por ligar os componentes e promover a circulação da energia entre eles. Existem distintas divisões de cabos dentro do sistema fotovoltaico ongrid. "A NBR 16.612 é a norma que regulamenta os requisitos mínimos para a qualificação e aceitação de cabos para uso em corrente contínua em instalações de energia fotovoltaica". Já "a NBR-5410, é a norma que auxilia nesta avaliação. No geral, ela estabelece as condições que devem satisfazer as instalações a fim de garantir a segurança das pessoas e animais que habitam a instalação, funcionamento e conservação dos bens".

d) Dispositivos de proteção: são considerados requisitos de segurança do sistema fotovoltaico. Existem dispositivos de proteção para corrente contínua (CC), que ficam entre os módulos fotovoltaicos e a entrada do inversor, e dispositivos de proteção para corrente alternada (CA), que ficam entre a saída do inversor e a conexão com o quadro elétrico da UC. A NBR 5410 prevê que não se deve misturar circuitos CA e CC na mesma "caixa" (string box). Nesse sentido, para garantir uma condição de segurança mínima, também é

\footnotetext{
5 Documentos da Consulta pública e a Lista de contribuições podem ser acessados em: https://www.aneel.gov.br/consultas-publicas (procurar consultas públicas encerradas).

${ }^{6}$ Documento da Secretaria de Avaliação, Planejamento, Energia e Loteria (Secap) do Ministério da Economia, a favor da revisão das regras, intitulado "Visão da Secap sobre o setor de energia: o caso da micro e minigeração distribuída", está disponível em: https://www.gov.br/fazenda/pt-br/centrais-deconteudos/publicacoes/analises-e-estudos/arquivos/2019/visao-da-secap-sobre-o-setor-de-energia-o-caso-
} da-micro-e-minigeracao-distribuida. 
necessário atender a NBR 16690, que especifica os requisitos de segurança dos sistemas em corrente contínua.

e) Inversor: realiza a conversão ${ }^{7}$ da corrente contínua produzida pelos módulos fotovoltaicos em corrente alternada. Todavia, a funcionalidade dos inversores é cada vez mais abrangente e importante: eles regulam, por exemplo, a tensão e a frequência do sistema, assim como garantem a segurança e o fluxo regular de eletricidade. Existem diversos modelos de inversores no mercado, mas eles devem possuir certificação do INMETRO (Instituto Nacional de Metrologia, Normalização e Qualidade Industrial) para serem comercializados, sejam eles de fabricação nacional ou importados.

f) Medidor bidirecional: é utilizado para saber o quanto de energia está sendo gerada pelo sistema e o quanto está sendo consumida pela UC.

g) Rede da concessionária: a energia produzida é conduzida para a rede de energia da concessionária local, que é responsável por operacionalizar ${ }^{8} 0$ sistema de compensação.

\section{ESTUDO DE CASO}

O método adotado foi o estudo de caso, que "consiste no estudo profundo e exaustivo de um ou poucos casos, de maneira que permita seu amplo e detalhado conhecimento" (GIL, 2017, p. 34). O caso proposto é o do investimento em um sistema fotovoltaico do tipo on grid em uma panificadora localizada no município de Camocim de São Félix - Pernambuco. O prédio no qual funciona o empreendimento pertence ao cliente, é o mais alto dos vizinhos e não apresenta sombreamento.

Nos últimos anos foi percebido um custo bastante elevado do consumo de energia elétrica no empreendimento, intensificado, principalmente, pelas constantes variações do preço de energia. Assim, o sistema em questão foi desenvolvido com a perspectiva de se apresentar como uma solução viável para os altos custos de energia elétrica, e se possível, deste modo, possibilitar que a padaria se torne autossuficiente na produção de energia.

\section{Coleta de dados}

Foi requerida uma conta elétrica do estabelecimento e com ela foi encontrado o histórico de consumo no site da distribuidora do Estado, a CELPE. A amostra de dados contemplou faturas com datas referentes a abril de 2015 até abril de 2016 (período anterior à instalação da usina) e abril de 2019 até abril de 2020 (período com a usina já instalada). Em paralelo, foi feito o levantamento do custo do sistema fotovoltaico em questão junto aos proprietários.

\section{Análise de viabilidade econômica}

Para a análise de viabilidade econômica foram utilizados os métodos de análise de investimento: o Valor Presente Líquido (VPL), a Taxa Interna de Retorno (TIR) e o Payback simples.

O método VPL é "a diferença entre o valor presente do projeto e o custo do projeto na data atual. VPL positivo significa que o projeto vale mais do que custa, ou seja, é lucrativo. VPL negativo significa que o projeto custa mais do que vale, ou seja, se for

\footnotetext{
7 "A energia elétrica gerada por um sistema de energia solar fotovoltaica é em corrente contínua (CC), enquanto que a eletricidade da nossa casa e dos postes é em corrente alternada (CA). Se estas duas energias são conectadas, pode ocorrer um evento catastrófico na rede" (ENERGÊS, 2020 online).

8 "Essa operacionalização se dá desde a divulgação das regras especificas para a conexão da geração distribuída em suas redes, passando pela avaliação e aprovação dos projetos, compra e instalação dos sistemas de medição, até a operação propriamente dita do sistema" (DANTAS, 2020, p. 26).
} 
implementado, trará prejuízo" (ABREU FILHO et al, 2007, p.83). Essa taxa também é chamada de taxa de desconto, custo de oportunidade ou custo de capital (GITMAN, 2002).

O segundo método, a TIR de um investimento, tem a finalidade de encontrar uma taxa de retorno para o investimento proposto. Em outras palavras, a TIR faz com que o valor presente líquido de uma oportunidade de investimento se iguale a zero (GITMAN, 2002).

O método Payback, por sua vez, de acordo com Abreu Filho (2007), mostra quanto tempo um investimento leva para retornar os valores investidos.

\section{Sistema de Bandeiras Tarifárias}

Por estabelecimento da ANEEL, desde 2015, as contas de energia apresentam o sistema de Bandeiras Tarifárias, "que apresenta as seguintes modalidades: verde, amarela e vermelha - as mesmas cores dos semáforos - e indicam se haverá ou não acréscimo no valor da energia a ser repassada ao consumidor final, em função das condições de geração de eletricidade" (ANEEL, 2019 online). Cada modalidade apresenta as seguintes características:

Bandeira verde: condições favoráveis de geração de energia. A tarifa não sofre nenhum acréscimo;

Bandeira amarela: condições de geração menos favoráveis. A tarifa sofre acréscimo de $R \$ 0,01343$ para cada quilowatt-hora $(\mathrm{kWh})$ consumidos;

Bandeira vermelha - Patamar 1: condições mais custosas de geração. A tarifa sofre acréscimo de $\mathrm{R} \$ 0,04169$ para cada quilowatt-hora $\mathrm{kWh}$ consumido.

Bandeira vermelha - Patamar 2: condições ainda mais custosas de geração. A tarifa sofre acréscimo de $R \$ 0,06243$ para cada quilowatt-hora kWh consumido (ANEEL, 2019 online).

Todos as unidades consumidoras cativas das distribuidoras são faturadas pelo Sistema de Bandeiras Tarifárias, com exceção daquelas localizadas no Estado de Roraima.

\section{$4 \quad$ RESULTADOS E DISCUSSÃO}

Os módulos fotovoltaicos ocupam uma área de $670 \mathrm{~m}^{2}$. O detalhamento do sistema de geração e do investimento é apresentado no quadro 3 :

Quadro 3: Dados gerais do sistema de geração e do investimento

\begin{tabular}{|l|c|l|c|}
\hline \multicolumn{1}{|c|}{ Produto } & Quant. & \multicolumn{1}{|c|}{ Descrição } & Valor Total \\
\hline Gerador fotovotaico com & 1 & Composição do sistema fotovoltaico: & $426.000,00$ \\
capacidade de gerar & & -415 módulos fotovoltaicos de 270 Wp & (quatrocento \\
$79,20 \mathrm{kWp}$ mas limitado & & do fabricante SOLUXTEC, modelo & s e vinte e \\
a injeção de 75 kW no & & DAS MODUL Mono Serie FR60 270 & seis mil \\
sistema de distribuição da & & reais) \\
Celpe. & & -3 inversores modelo Eco 25.03-S, & \\
& & Fabricante FRONIUS com Potência & \\
& unitária de 25 kWp e potência total de & \\
& 75 kWp; & \\
& - Estrutura de suporte; & \\
& - Serviço de instalação, mão de obra e & \\
& demais materiais. & \\
\hline
\end{tabular}

Fonte: Dados da pesquisa. 
Na Tabela 1 é possível verificar: o valor do consumo, a tarifa, o preço e a bandeira tarifária de cada mês, antes da instalação da usina.

Tabela 1: Dados de consumo e custo com energia elétrica do consumidor

\begin{tabular}{|c|c|c|c|}
\hline Mês/Ano & $\begin{array}{c}\text { Consumo KWH/ } \\
\text { Mês }\end{array}$ & $\begin{array}{c}\text { Valor KWh } \\
\text { (com imposto) }\end{array}$ & $\begin{array}{c}\text { Custo Conta/ } \\
\text { Mês }\end{array}$ \\
\hline abril-16 & 13.325 & 0,80 & 10.660 \\
\hline março-16 & 12.752 & 0,80 & 10.202 \\
\hline fevereiro-16 & 13.074 & 0,80 & 10.459 \\
\hline janeiro-16 & 13.001 & 0,80 & 10.401 \\
\hline dezembro-15 & 13.427 & 0,80 & 10.742 \\
\hline novembro-15 & 12.662 & 0,80 & 10.130 \\
\hline outubro-15 & 12.372 & 0,80 & 9.898 \\
\hline setembro-15 & 12.440 & 0,80 & 9.952 \\
\hline agosto-15 & 11.951 & 0,80 & 9.561 \\
\hline julho-15 & 12.430 & 0,80 & 9.944 \\
\hline junho-15 & 13.575 & 0,80 & 10.860 \\
\hline maio-15 & 12.936 & 0,80 & 10.349 \\
\hline abril-15 & 13.026 & 0,80 & 10.421 \\
\hline Média & 12.844 & 0,80 & 10.275 \\
\hline
\end{tabular}

Fonte: Dados da pesquisa (conta de energia do consumidor).

Na Tabela 2 é possível verificar: o valor do consumo, a tarifa, o preço e a bandeira tarifária de cada mês, após a instalação da usina.

Tabela 2: Dados de consumo e custo com energia elétrica do consumidor

\begin{tabular}{|c|c|c|c|c|}
\hline Mês/Ano & $\begin{array}{c}\text { Consumo } \\
\text { KWH/ } \\
\text { Mês }\end{array}$ & $\begin{array}{c}\text { Valor KWh } \\
\text { (com imposto) }\end{array}$ & $\begin{array}{c}\text { Custo Conta/ } \\
\text { Mês }\end{array}$ & $\begin{array}{c}\text { Economia de } \\
\text { energia (R\$) }\end{array}$ \\
\hline abril-20 & 8.420 & 0,80 & 6.736 & 3.924 \\
\hline março-20 & 6.143 & 0,80 & 4.914 & 5.287 \\
\hline fevereiro-20 & 6.912 & 0,80 & 5.530 & 4.930 \\
\hline janeiro-20 & 6.562 & 0,80 & 5.250 & 5.151 \\
\hline dezembro-19 & 7.579 & 0,80 & 6.063 & 4.678 \\
\hline novembro-19 & 6.775 & 0,80 & 5.420 & 4.710 \\
\hline outubro-19 & 7.459 & 0,80 & 5.967 & 3.930 \\
\hline setembro-19 & 6.562 & 0,80 & 5.250 & 4.702 \\
\hline agosto-19 & 6.707 & 0,80 & 5.366 & 4.195 \\
\hline julho-19 & 7.245 & 0,80 & 5.796 & 4.148 \\
\hline junho-19 & 7.611 & 0,80 & 6.089 & 4.771 \\
\hline maio-19 & 7.464 & 0,80 & 5.971 & 4.378 \\
\hline abril-19 & 7.201 & 0,80 & 5.761 & 4.660 \\
\hline Média & $\mathbf{7 . 1 2 6}$ & 0,80 & $\mathbf{5 . 7 0 1}$ & $\mathbf{4 . 5 7 4}$ \\
\hline
\end{tabular}

Fonte: Dados da pesquisa (conta de energia do consumidor). 
Tabela 3: Dados do investimento na usina no ano 0 e dos valores economizados do ano 1 ao 25

\begin{tabular}{|l|c|l|c|l|c|}
\hline ANO & VALOR $(\mathrm{R} \$)$ & ANO & VALOR $(\mathrm{R} \$)$ & ANO & VALOR (R\$) \\
\hline 0 & -426.000 & 9 & 54.891 & 18 & 54.891 \\
\hline 1 & 54.891 & 10 & 54.891 & 19 & 54.891 \\
\hline 2 & 54.891 & 11 & 54.891 & 20 & 54.891 \\
\hline 3 & 54.891 & 12 & 54.891 & 21 & 54.891 \\
\hline 4 & 54.891 & 13 & 54.891 & 22 & 54.891 \\
\hline 5 & 54.891 & 14 & 54.891 & 23 & 54.891 \\
\hline 6 & 54.891 & 15 & 54.891 & 24 & 54.891 \\
\hline 7 & 54.891 & 16 & 54.891 & 25 & 54.891 \\
\hline 8 & 54.891 & 17 & 54.891 & & \\
\hline
\end{tabular}

Fonte: Elaborada pelos autores.

Considerando-se a TMA (Taxa mínima de atratividade) de 5,046\% a.a., obtida pela média da taxa CDI dos anos de 2018, 2019 e 2020, e de posse dos dados acima, que representam os valores do investimento no ano 0 (ano de instalação da usina) - de $R \$$ 426.000,00 -, e dos valores economizados pelo consumidor nos 25 anos seguintes, correspondentes ao período de vida útil das placas, obtêm-se o Valor presente líquido VPL de R\$ 770.062,98.

Utilizando-se os dados da Tabela 3, obtêm-se a Taxa interna de retorno - TIR de $12,15 \%$ a.a.

Tabela 4: Cálculo do PAYBACK simples

\begin{tabular}{|l|l|l|l|l|l|}
\hline ANO & VALOR $(\mathrm{R} \$)$ & ANO & VALOR $(\mathrm{R} \$)$ & ANO & VALOR (R\$) \\
\hline 0 & -426.000 & 9 & 68.015 & 18 & 562.031 \\
\hline 1 & -371.109 & 10 & 122.906 & 19 & 616.921 \\
\hline 2 & -316.219 & 11 & 177.796 & 20 & 671.812 \\
\hline 3 & -261.328 & 12 & 232.687 & 21 & 726.702 \\
\hline 4 & -206.438 & 13 & 287.578 & 22 & 781.593 \\
\hline 5 & -151.547 & 14 & 342.468 & 23 & 836.483 \\
\hline 6 & -96.656 & 15 & 397.359 & 24 & 891.374 \\
\hline 7 & -41.766 & 16 & 452.249 & 25 & 946.265 \\
\hline 8 & 13.125 & 17 & 507.140 & & \\
\hline
\end{tabular}

Fonte: Elaborada pelos autores.

\section{CONSIDERAÇÕES FINAIS}

Dentro do estudo da viabilidade, foram utilizados três indicadores econômicos: o payback, o valor presente líquido (VPL) e a taxa interna de retorno (TIR). O tempo de retorno (payback) do investimento está entre 7 e 8 anos, o que representa um tempo de retorno $32,00 \%$ em relação à vida útil dos painéis fotovoltaicos, que é de 25 anos. Conforme a análise do VPL, o investimento será rentável entre 10 a 11 anos, período em que o VPL passa a ser positivo, produzindo ao fim da vida útil do projeto, um fluxo de caixa positivo de

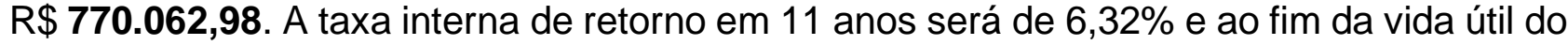
projeto será de $12,15 \%$, ou seja, a partir do $11^{\circ}$ ano o TIR é maior que a TMA, sendo o investimento considerado atraente. 
Este artigo não pretende esgotar o tema em questão, assim como, em função da metodologia adotada, generalizar os achados. Além disso, sugere-se novos estudos enfocando, por exemplo, a sustentabilidade no que se refere às dimensões sociais e/ou ambientais, que não foram exploradas no presente texto.

\section{REFERÊNCIAS}

ABREU FILHO, J. C. et al. Finanças corporativas. 8.ed.- reimpressão. Rio de Janeiro: Editora FGV, 2007.

ABSOLAR. Associação Brasileira de Energia Solar Fotovoltaica. Baterias - Garantia de operação segura à noite e em dias nublados, 2017. Disponível em:

https://www.absolar.org.br/noticia/baterias-garantia-de-operacao-segura-a-noite-e-emdias-nublados/. Acesso em: 12 fev. 2021.

ABSOLAR. Associação Brasileira de Energia Solar Fotovoltaica. Especialista traça perspectivas para o futuro do armazenamento no Brasil, 2020a. Disponível em: https://www.absolar.org.br/noticia/especialista-traca-perspectivas-para-o-futuro-doarmazenamento-no-brasil/. Acesso em: 12 fev. 2021.

ABSOLAR. Associação Brasileira de Energia Solar Fotovoltaica. Estatísticas e análises exclusivas do mercado solar fotovoltaico, 2020b. Disponível em:

https://www.absolar.org.br/mercado/. Acesso em: 09 fev. 2021.

ANEEL. Agência Nacional de Energia Elétrica. Bandeiras Tarifárias - SGT publicado em: 24/11/2015; última modificação em: 12/11/2019. Disponível em:

https://www.aneel.gov.br/bandeiras-tarifarias. Acesso em: 29 mar. 2021.

ANEEL. Agência Nacional de Energia Elétrica. Procedimentos de Distribuição de Energia Elétrica no Sistema Elétrico Nacional - PRODIST. Módulo 3 - Acesso ao Sistema de Distribuição, 2017. Disponível em: https://www.aneel.gov.br/modulo-3. Acesso em: 30 nov. 2019.

ANEEL. Agência Nacional de Energia Elétrica. Micro e minigeração distribuída: sistema de compensação de energia elétrica. 2. ed. - Brasília: ANEEL, 2016.

BRASIL. Ministério de Minas e Energia. Agência Nacional de Energia Elétrica. Resolução Normativa № 482, de 17 de abril de 2012. Estabelece as condições gerais para o acesso de microgeração e minigeração distribuída aos sistemas de distribuição de energia elétrica, o sistema de compensação de energia elétrica, e dá outras providências. Diário Oficial da União, ed. 76, seção 1, Brasília, DF, p. 53, 19 de abr. 2012.

BRASIL. Ministério de Minas e Energia. Agência Nacional de Energia Elétrica. Resolução Normativa № 687, de 24 de novembro de 2015. Altera a Resolução Normativa ํㅡ 482, de 17 de abril de 2012, e os Módulos 1 e 3 dos Procedimentos de Distribuição - PRODIST.

Diário Oficial da União, ed. 230, seção 1, Brasília, DF, p. 45, 2 de dez. 2015.

DANTAS, S. G. Oportunidades e desafios da geração solar fotovoltaica no

Semiárido do Brasil. Texto para Discussão, n. 2541. Brasília: Ipea, 2020. 
ENERGÊS. Do início ao fim sistema solar fotovoltaico on-grid. [s.l.], 14 abr. 2020. Disponível em: https://energes.com.br/fale-energes/sistema-solar-fotovoltaico-on-grid/. Acesso em: 30 nov. 2019.

EPE. Empresa de Pesquisa Energética. Balanço Energético Nacional Interativo (BEN Interativo), 2020. Disponível em: https://www.epe.gov.br/pt/publicacoes-dadosabertos/publicacoes/balanco-energetico-nacional-interativo. Acesso em: 09 fev. 2021.

GIL, A. C. Como elaborar projetos de pesquisa. 6. ed. São Paulo: Atlas, 2017.

GITMAN, L. J. Princípios de administração financeira. 12. ed. São Paulo: Person Prentice Hall, 2010.

PEREIRA, E. B. et al. Atlas brasileiro de energia solar. 2.ed. São José dos Campos: INPE, 2017. 80p.

SILVA, R. M. O novo arranjo regulatório proposto pela Aneel para a geração distribuída na Consulta Pública n 25. Boletim Legislativo nำ 82, out., 2019. Disponível em: https://www12.senado.leg.br/publicacoes/estudos-legislativos/tipos-deestudos/boletins-legislativos/bol82/view. Acesso em: 12 fev. 2021.

\title{
EVALUATION OF THE IMPLEMENTATION OF A PHOTOVOLTAIC SYSTEM IN THE BAKERY SECTOR
}

\begin{abstract}
The present work evaluates the implementation of a photovoltaic generation system to supply all the electrical energy consumption of a commercial enterprise in the bakery sector. The system in question was developed with the perspective of presenting itself as a viable solution to the high costs of electricity that the enterprise has had in recent years, and if possible, in this way, become self-sufficient in energy production. Thus, through a case study research, the following data was collected: tariff, cost and energy consumption of the bakery. For the economic feasibility analysis the following investment analysis methods were used: net present value, internal rate of return and payback. It was possible to verify that in fact there is viability in the implementation of the photovoltaic generation system in the enterprise.
\end{abstract}

Keywords: photovoltaic system, distributed generation, bakery sector. 